Article

\title{
Effects of Pulp Fiber and Epoxidized Tung Oil Content on the Properties of Biocomposites Based on Polylactic Acid
}

\author{
Van Khoi Nguyen *, Thanh Tung Nguyen *, Thu Ha Pham Thi and Thu Trang Pham (D) \\ Institute of Chemistry, VAST, 18 Hoang Quoc Viet, Cau Giay, Ha Noi 122300, Vietnam; \\ haptt6@gmail.com (T.H.P.T.); thutrang90vhh@gmail.com (T.T.P.) \\ * Correspondence: khoinguyen56@gmail.com (V.K.N.); nttung@ich.vast.vn (T.T.N.); \\ Tel.: +84-904141011 (V.K.N.); +84-901333885 (T.T.N.)
}

Received: 13 April 2020; Accepted: 15 May 2020; Published: 19 May 2020

\begin{abstract}
Recently, various environmental-friendly materials have been investigated and developed, especially composites of polylactic acid (PLA) and plant fibers. This paper investigates the effects of pulp fiber (PF) and epoxidized Tung oil (ETO) content on the properties of biocomposites, based on polylactic acid. The bleached pulp fiber reinforced PLA (PLA/PF) composites with 10-50 wt $\%$ fiber contents and $0-15 \%$ epoxidized Tung oil contents (with a certain number of fiber) were prepared in an internal mixer (Plastograph ${ }^{\circledR} \mathrm{EC}$ ) at $150^{\circ} \mathrm{C}$. The mechanical properties of PLA/PF composites were improved significantly. The pulp fiber reinforced PLA composites, with the fiber content of $30 \mathrm{wt} \%$, were found to have the highest mechanical properties. The tensile and flexural properties of PLA/Tung oil-soaked-pulp fiber composites were higher than those of PLA/Tung oil unsoaked pulp fiber composites. In addition, the degradation temperature of PLA-based composites decreased after adding more pulp fiber. The pulp fibers were well-dispersed in the PLA matrix with the content up to $30 \mathrm{wt} \%$. The interaction between pulp fiber and PLA matrix improved by the addition of epoxidized Tung oil. Epoxidized Tung oil also improved tensile and flexural strength of composite materials when it was added with a number of below $10 \%$ of fiber.
\end{abstract}

Keywords: poly (lactic acid); pulp fiber; natural fiber reinforced composites; epoxidized Tung oil

\section{Introduction}

Over the last few decades, the natural fiber, reinforced polymer composites, have rapidly grown and are now widely used in the academic and industrial applications due to the advantages of natural fibers, such as low density, lightweight, renewability, high specific strength, enhanced energy recovery, good thermal properties, non-toxicity, low cost and biodegradability [1]. The natural fiber reinforced composites are used in various applications, such as transportation, building and construction materials, packaging, consumer products, etc. due to their environmentally-friendly properties [2]. Natural fibers, which are commonly used as reinforcement for polymer composites, include abaca, jute, kenaf, coir, cotton, bamboo, flax, hemp, ramie, sisal, banana, etc. [3,4]. Despite the advantages, natural fibers, used as reinforcement agents, also have some disadvantages, such as high moisture absorbtion, poor wettability, and incompatibility with polymeric matrices [1]. Recently, chemical treatment methods have been used to improve the compatibility between natural fibers and polymer matrix, such as alkaline treatment, coupling agents (silanes, acetylation, graft copolymerization), bleaching, enzyme, etc. This increases the interaction between fibers and polymer matrix, as well as improves the mechanical properties of the composites.

One of the most widely investigated polymers to replace petroleum-based polymers is PLA because of its favorable properties, namely good mechanical properties, biocompatibility, biodegradability, 
and especially the use of the same technological equipment as what used for conventional fiber reinforced composite materials. In addition, PLA can be made from renewable resources, for example, maize, sugarbeet, rice, etc. In the recent years, many studies concentrate on the performance of PLA with different natural fibers, such as flax fiber [5-7], jute [8,9], kenaf [10-12], abaca fiber [13] and hemp [14]. Pulp fibers are also a good option for reinforcement composites because of their availability, uniform quality and cheaper price than agro fibers. Zhaozhe Y. et al. found that the tensile and flexural modulus of the PLA composites with wood fiber and pulp fiber were greater than those of pure PLA, and pulp fiber improved the properties of the composites better than wood fiber [15]. Kirsi Immoen et al. fabricated PLA composite with softwwood kraft pulp using epoxidized linseed oil (ELO) as a plasticizer and a platicizer-coupling agent. The results showed that ELO improved, not only the interaction between pulp fiber and PLA, but also the tensile strength of composites by using at 5-8\% content of ELO [16]. Heidi Peltola et al. found that epoxidized linseed oil, not only promotes the adhesion of PLA wood pulp, but also reduces fiber loss during melting processing [17]. Research also showed that unbleached fibers had a stronger reinforcement effect than bleached fibers.

However, hydrophilic cellulose fibers are difficult to disperse equally and to interact with the PLA matrix. A commonly used method to increase the interaction between fiber and polymer is adding plasticizers, especially vegetable oil-based plasticizers because of its availability, biodegradability, and low cost. Among vegetable oils, Tung oil is widely used in the industry, especially in the field of paints and plastics due to its high heat resistance, water resistance and salinity tolerance. Moreover, as one of oil with the highest iodine index [18], Tung oil promises good results when used as a plasticizer for PLA/pulp fiber composites. The aim of this study is to study the effects of pulp fiber and epoxidized Tung oil content on the properties of biocomposites, based on polylactic acid.

\section{Materials and Methods}

\subsection{Materials}

Poly (lactic acid) (PLA) resin produced by SMBEST Pvt. Ltd. (Busan, Korea) was used as the matrix material. Its density was $1.2-1.31 \mathrm{~g} / \mathrm{cm}^{3}$, and its melt flow index (MFI) was below $5 \mathrm{~g} / 10 \mathrm{~min}$ at $5 \mathrm{~kg} / 190^{\circ} \mathrm{C}$. In terms of the reinforcement materials, bleached pulp fibers were initially supplied by An Hoa Paper Joint Stock Company (Tuyen Quang, Viet Nam) then cut to the size of 3-4 mm. The properties of bleached pulp fibers were listed in Table 1.

Table 1. The properties of bleached pulp fibers.

\begin{tabular}{cc}
\hline Properties & Value \\
\hline$\alpha$-cellulose, $\%$ & $96.7 \pm 0.5$ \\
\hline Lignin, $\%$ & $0.27 \pm 0.08$ \\
\hline Viscosity, $\mathrm{ml} / \mathrm{g}$ & 655 \\
\hline Ash, $\%$ & $0.28 \pm 0.05$ \\
\hline
\end{tabular}

Tung oil was supplied by Vietnam Tung oil company limited (Ha Noi, Viet Nam). The properties of Tung oil were listed in Table 2. Amberlite ${ }^{\circledR}$ IRC120 H, hydrogen form $15 \mathrm{wt} \%$ to oil (Sigma), $\mathrm{H}_{2} \mathrm{O}_{2}$ (Sigma) and acetic acid (Sigma) were used to modified Tung oil. 
Table 2. The properties of Tung oil.

\begin{tabular}{cc}
\hline Properties & Value \\
\hline Density $\left(\right.$ at $\left.20{ }^{\circ} \mathrm{C}\right)$ & $0.920-0.945$ \\
\hline Acid value & 1.4 \\
\hline Iodine value & $149.5-170.6$ \\
\hline Saponification value & $193.4-196.7$ \\
\hline
\end{tabular}

To prepare epoxidized Tung oil, Tung oil was stirred in a flask and heated to $55^{\circ} \mathrm{C}$ in the presence of Amberlite ${ }^{\circledR}$ IRC120 Has the catalyst with a uniform agitation under the constant stirring speed of $1600 \mathrm{rpm}$. A mixture of $\mathrm{H}_{2} \mathrm{O}_{2}$ and acetic acid was dropwise added into the mixture of Tung oil and Amberlite ${ }^{\circledR}$ IRC120 at a constant rate for $2 \mathrm{~h}$. The reaction time was $5 \mathrm{~h}$ and the ratio of Tung oil/acid acetic $/ \mathrm{H}_{2} \mathrm{O}_{2}$ was 1.0/0.5/0.5. At the end of the reaction, the mixture was cooled and centrifuged at least $5 \mathrm{~min}$ under the rotation speed of $2000 \mathrm{rpm}$. The oil phase, separated from the aqueous phase and the catalyst, was washed with distilled water until acid free, and evaporated for at least $1 \mathrm{~h}$ under the vacuum of about $40 \mathrm{mbar}$ at $60^{\circ} \mathrm{C}$ [19]. Epoxy value was determined by titration method according to TY-6-10-722-72. Epoxy value of epoxidized Tung oil was $6.8 \%$.

\subsection{Composite Preparation}

The PLA resin and pulp fibers were dried at $80{ }^{\circ} \mathrm{C}$ for $5 \mathrm{~h}$ under vacuum. PLA/pulp fiber composites were manufactured according to two methods (Figure 1): (1) Pulp fiber (NPF), epoxidized Tung oil and PLA were mixed directly; (2) epoxidized Tung oil soaked pulp fibers (SPF) were mixed with PLA (Sce. To soak the pulp fibers with epoxidized Tung oil, epoxidized Tung oil was dissolved in methyl ethyl ketone (ratio of 1/20) and sprayed onto the pulp. After that, the mixtures were dried in an oven at $80^{\circ} \mathrm{C}$ for $5 \mathrm{~h}$ for the reaction between Tung oil and pulp fiber to take place.

Method 1:

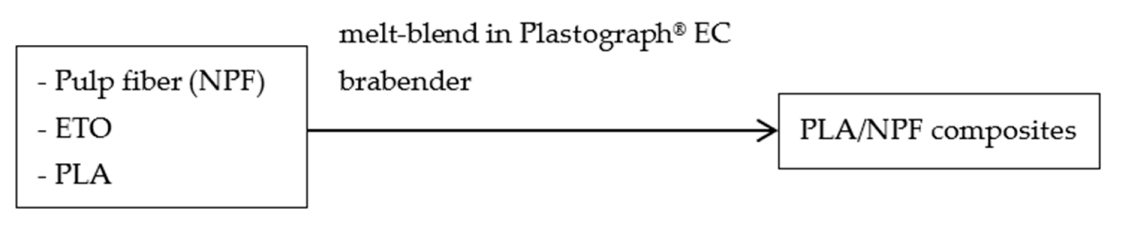

Method 2:

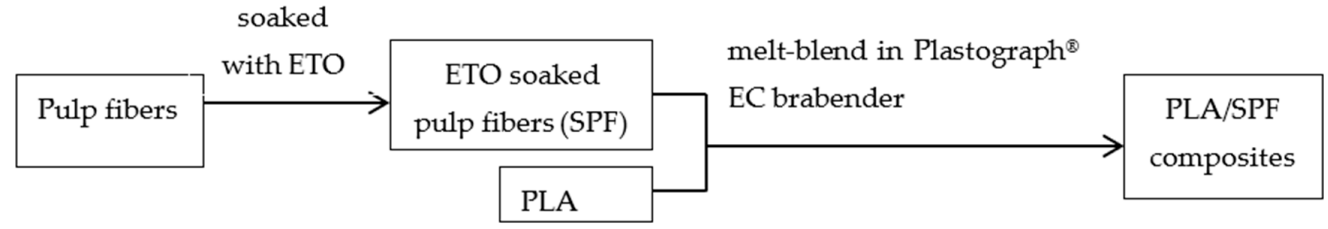

Figure 1. Two fabricating methods for Poly (lactic acid) (PLA)/pulp fiber (PF) composites.

The separated pulp fibers and epoxidized Tung oil or epoxidized Tung oil-soaked pulp fibers were melt-blended with PLA resin in an internal mixer model Plastograph ${ }^{\circledR}$ EC (Duisburg, Germany) at $150{ }^{\circ} \mathrm{C}$ with a rotor speed of $50 \mathrm{rpm}$ for $6 \mathrm{~min}$. The pulp fiber/PLA composites were compressed and moulded into 3-mm-thick plates on a GoTech hot press at $170{ }^{\circ} \mathrm{C}$ at a pressure of 50 psi for $5 \mathrm{~min}$. Moulded samples were cut into specimens according to ASTM D638 and ISO 178 to determine tensile properties and flexural properties respectively. To study the effect of pulp fiber contents on the properties of composite, the pulp fibers were adding into PLA with different fiber contents $(0 \%, 10 \%$, $20 \%, 30 \%, 40 \%$ and $50 \%$ ) in the presence of epoxidized Tung oil (in amount of $10 \%$ of fiber). To study the effect of pulp fiber contents on the properties of composite, the used epoxidized Tung oil contents were $0 \%, 5 \%, 7.5 \%, 10 \%, 15 \%$, respectively. 


\subsection{Characterization of Composites}

\subsubsection{Mechanical Properties}

Tensile test was determined by ASTM D638 at a crosshead speed of $50 \mathrm{~mm} / \mathrm{min}$ by using Instron 5980 Testing Machine (Illinois Tool Works Inc., Norwood, MA, USA). Flexural test was carried out on Instron 3382 (American) according to ISO 187. All the test samples were stabilized at a room temperature for $24 \mathrm{~h}$ before testing. An average value of five tests was reported.

\subsubsection{Scanning Electron Microscope (SEM)}

The fracture surface morphology of the pulp fiber reinforced PLA composites was investigated by using a scanning electron microscope SEM (JEOL 6490, Tokyo, Japan) at $15 \mathrm{kV}$. The fracture surface of the samples was coated with platinum before examination.

\subsubsection{Fourier Transfer Infrared Spectra (FTIR)}

The IR spectra of composites was analysed with a Fourier transform infra-red (FTIR) spectrometer (Nicolet Impact model 410, Nicolet, Madison, WI, USA). The equipment was operated with a resolution of $4 \mathrm{~cm}^{-1}$ and scanning range from 4000 to $500 \mathrm{~cm}^{-1}$.

\subsubsection{Thermogravimetry Analysis (TGA)}

Thermogravimetry analysis was carried out at $10{ }^{\circ} \mathrm{C} / \mathrm{min}$ heating rate in the air, from room temperature to $550^{\circ} \mathrm{C}$ on a thermogravimetry analysis system TGA209F1 (Netzch, Selb, Germany).

\subsubsection{Differential Scanning Calorimetry (DSC)}

Differential scanning calorimetry analysis was conducted using NETZSCH DSC 204F1 Phoneix (Netzsch, Selb, Germany). The sample was heated at a rate of $10{ }^{\circ} \mathrm{C} / \mathrm{min}$ from $\mathrm{rt}$ to $200{ }^{\circ} \mathrm{C}$, followed by cooling at $10^{\circ} \mathrm{C} / \mathrm{min}$ to $\mathrm{rt}$.

\section{Results and Discussions}

\subsection{Effect of Pulp Fiber Contents}

\subsubsection{Mechanical Properties of Composites}

In this study, the samples were prepared with different pulp fiber contents (ranging from $0 \%$ to $50 \%$ ), and the epoxidized Tung oil was fixed at $10 \%$ of fiber. The mechanical properties of neat PLA and PLA/PF composites were presented in Table 3.

Table 3. Effect of pulp fiber contents on the mechanical properties of PLA/PF composites.

\begin{tabular}{ccccccc}
\hline $\begin{array}{c}\text { Composite } \\
\text { Fabrication } \\
\text { Method }\end{array}$ & $\begin{array}{c}\text { Pulp Fiber } \\
\text { Contents } \\
\mathbf{( \% )}\end{array}$ & $\begin{array}{c}\text { Tensile } \\
\text { Strength } \\
\mathbf{( M P a )}\end{array}$ & $\begin{array}{c}\text { Tensile Modulus } \\
\mathbf{( M P a})\end{array}$ & $\begin{array}{c}\text { Elongation } \\
\text { at Break (\%) }\end{array}$ & $\begin{array}{c}\text { Flexural } \\
\text { Strength } \\
\mathbf{( M P a )}\end{array}$ & $\begin{array}{c}\text { Flexural } \\
\text { Modulus } \\
\mathbf{( G P a )}\end{array}$ \\
\hline & 0 & $40.67 \pm 1.87$ & $2187.64 \pm 95.37$ & $11.70 \pm 0.41$ & $95.0 \pm 4.65$ & $2.91 \pm 0.12$ \\
\hline & 10 & $45.74 \pm 2.03$ & $2209.94 \pm 86.22$ & $11.63 \pm 0.53$ & $101.2 \pm 4.91$ & $3.14 \pm 0.09$ \\
\cline { 2 - 7 } & 20 & $51.62 \pm 1.94$ & $2482.22 \pm 101.05$ & $5.11 \pm 0.30$ & $103.6 \pm 5.02$ & $3.86 \pm 0.23$ \\
\cline { 2 - 7 } Method 1 & 30 & $56.61 \pm 2.11$ & $2809.67 \pm 90.43$ & $5.24 \pm 0.28$ & $109.5 \pm 6.36$ & $4.54 \pm 0.17$ \\
\cline { 2 - 7 } & 40 & $52.84 \pm 1.21$ & $3060.97 \pm 98.12$ & $2.54 \pm 0.20$ & $104.9 \pm 4.23$ & $5.09 \pm 0.20$ \\
\cline { 2 - 7 } & 50 & $42.87 \pm 1.53$ & $3542.66 \pm 88.96$ & $2.14 \pm 0.23$ & $103.3 \pm 5.64$ & $5.93 \pm 0.34$ \\
\hline
\end{tabular}


Table 3. Cont.

\begin{tabular}{ccccccc}
\hline $\begin{array}{c}\text { Composite } \\
\text { Fabrication } \\
\text { Method }\end{array}$ & $\begin{array}{c}\text { Pulp Fiber } \\
\text { Contents } \\
\mathbf{( \% )}\end{array}$ & $\begin{array}{c}\text { Tensile } \\
\text { Strength } \\
\mathbf{( M P a )}\end{array}$ & $\begin{array}{c}\text { Tensile Modulus } \\
\mathbf{( M P a )}\end{array}$ & $\begin{array}{c}\text { Elongation } \\
\text { at Break (\%) }\end{array}$ & $\begin{array}{c}\text { Flexural } \\
\text { Strength } \\
\mathbf{( M P a})\end{array}$ & $\begin{array}{c}\text { Flexural } \\
\text { Modulus } \\
\mathbf{( G P a )}\end{array}$ \\
\hline & 10 & $46.34 \pm 2.24$ & $2316.46 \pm 102.68$ & $11.71 \pm 0.39$ & $102.2 \pm 6.15$ & $3.21 \pm 0.25$ \\
\cline { 2 - 7 } & 20 & $52.88 \pm 1.96$ & $2502.19 \pm 93.14$ & $5.26 \pm 0.25$ & $105.0 \pm 5.28$ & $4.02 \pm 0.29$ \\
\cline { 2 - 7 } Method 2 & 30 & $59.32 \pm 2.35$ & $3043.54 \pm 96.52$ & $5.13 \pm 0.31$ & $114.7 \pm 3.67$ & $4.97 \pm 0.18$ \\
\cline { 2 - 7 } & 40 & $55.45 \pm 2.41$ & $3390.27 \pm 99.45$ & $2.64 \pm 0.18$ & $108.8 \pm 4.82$ & $5.85 \pm 0.10$ \\
\cline { 2 - 7 } & 50 & $50.28 \pm 2.07$ & $3751.38 \pm 92.47$ & $2.23 \pm 0.24$ & $106.5 \pm 5.26$ & $6.18 \pm 0.32$ \\
\hline
\end{tabular}

It can be seen that the tensile strength of neat PLA is lower than that of PLA/PF composites. The tensile strength of PLA/PF composites increased significantly by increasing the percentage of pulp fiber content up to $30 \mathrm{wt} \%$ and then decreased by further addition of pulp fiber. When the pulp fiber contents were from 10 to $30 \%$, the tensile strength of the composites increased from $45.74 \mathrm{MPa}$ to $56.61 \mathrm{MPa}$ (for PLA/NPF composites) and to 59.32 (for PLA/SPF composites). The increase of tensile modulus of PLA/PF composites was in proportion to the increase of pulp fiber content. These revealed that the addition of pulp fibers into PLA matrix provided effective reinforcement. This was because the stress was expected to transfer from the matrix to the strong fiber. Huda M. S. et al. suggested the better the alignment of the fibers, the higher the strength value [20]. However, when the pulp fiber was added to more than $30 \%$, the tensile properties of composite decreased. This might be due to the poor dispersion of fiber into the PLA matrix at higher pulp content. This result was consistent with the results of Jin Qian et al. for-cotton fiber/PLA composites [21]. However, Zhaozhe Yang et al. found that the tensile strength of both PLA/pulp fiber and PLA/wood fiber composites decreased with the increase of fiber content [15]. The results also showed that the tensile strength and modulus of composites, with untreated or soaked pulp fibers, were not significantly different with a fiber content of less than $30 \%$, but those of composites, containing soaked pulp fibers, were higher than those of composites containing untreated pulp fibers. This might be due to the fact that epoxidized Tung oil-treated pulp fibers were more evenly dispersed in PLA matrix, and Tung oil improved the interaction between PLA matrix and pulp fiber. The chemical interaction mechanism among epoxidized vegetable oil, PLA and natural fiber was proposed by Buong Woei Chieng et al. [22] (Figure 2) and Omid Nabinejad et al. [23] (Figure 3).

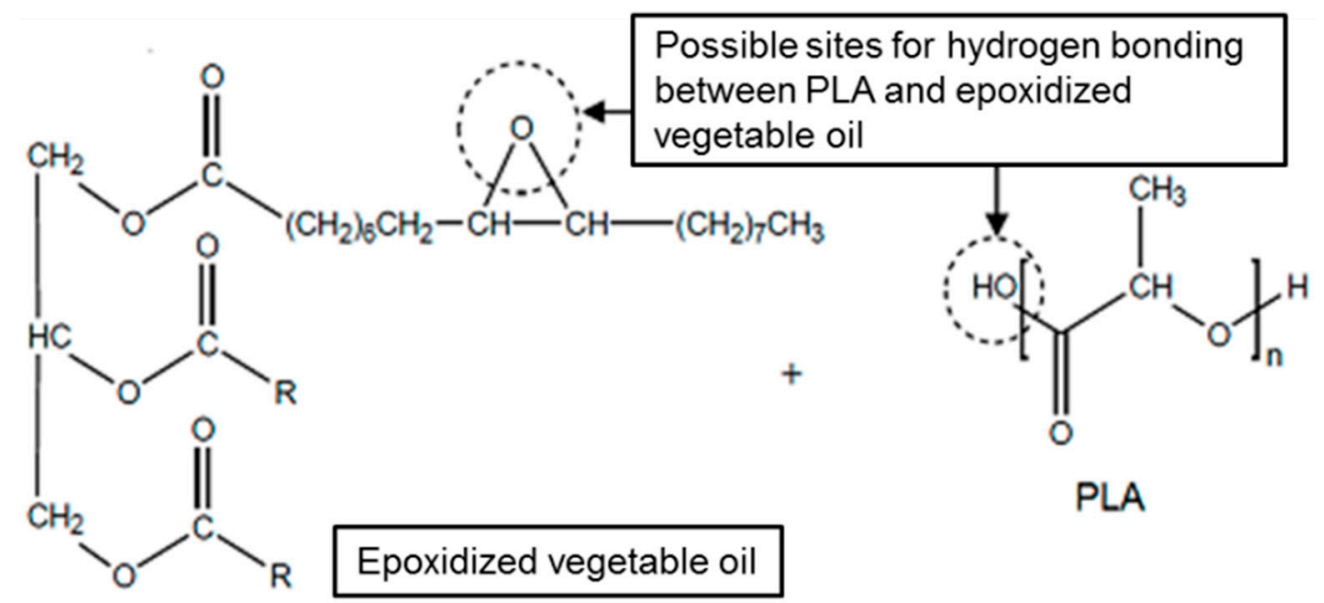

Figure 2. Suggested chemical interactions between epoxidized vegetable oil and PLA by Buong Woei Chieng et al. [22]. 


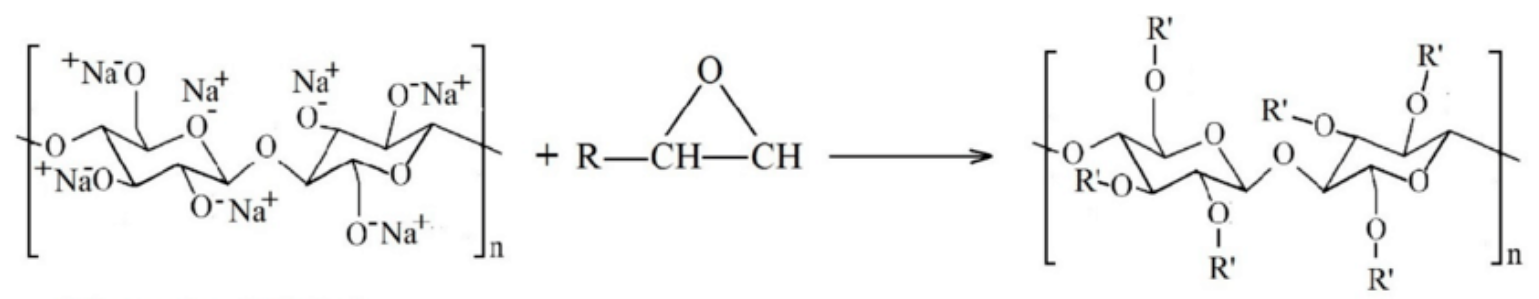

Mercerized Cellulose

$$
\text { Where } \mathrm{R}^{\prime} \text { is } \begin{gathered}
\mathrm{H} \\
\stackrel{\mathrm{O}}{\mathrm{C}}-\stackrel{\mathrm{O}}{\mathrm{C}}-\mathrm{I} \\
\mathrm{H}
\end{gathered}
$$

Figure 3. Suggested chemical interactions between epoxidized vegetable oil and mercerized natural fiber by Omid Nabinejad et al. [23].

Elongation at the break of the PLA/PF composites was also tested and shown in Table 3. The elongation at break of composites decreased as the fiber content in the composites increased.

According to the results, the flexural modulus of the composites increased significantly by increasing the pulp fiber content, while the flexural strength of the composite had non-significant change. However, both the flexural strength and flexural modulus of the composites were higher than that of the neat PLA. This could be explained that the addition of pulp fiber promoted the nucleation and crystallization of PLA matrix, so that the flexural modulus of the composites improved. This indicated that the pulp fiber acted as a rigid filler, which increased the stiffness of the composites. Similarly to the tensile properties, the flexural strength and modulus of PLA/SPF composites were slightly higher than that of PLA/NPF composites. When the content of pulp fiber was $30 \%$, the flexural strength of PLA/NPF and PLA/SPF composites reached 109.5 and 114.7 Mpa respectively, which increased by $15.3 \%$ and $20.7 \%$ compared with the pure PLA. This result was consistent with the results of Buket Okutan Baba and Ugur Özmen for chicken feather/PLA composites [24].

\subsubsection{Morphology Observation}

Figure 4 showed the fractured surfaces morphologies of PLA/NPF composites. As can be seen in Figure 4, there was a difference in the adhesion between NPF fiber and PLA matrix. At the lower fiber content, the voids between PLA matrix and NPF fiber were invisible. The composite containing 30\% of pulp fiber began to show voids between PLA matrix and NPF fiber. When the fiber content exceeded $30 \%$, the fiber breakages and the voids can be observed more clearly. The NPF fibers were pulled out from the PLA matrix, and the surface of PF fiber was not wrapped by PLA matrix. This suggested a poor adhesion between NPF fiber and PLA matrix.

Figure 5 showed that when treating pulp fiber with epoxidized Tung oil, the bonds between fibers and the PLA improved more significantly, compared to the untreated fibers. Even at $10 \%$ of fiber content, it was difficult to distinguish pulp fibers and PLA because the pulp fibers was covered by PLA. At 40 and $50 \%$ of fiber content, the gaps and holes between the SPF and PLA matrix can be observed. 


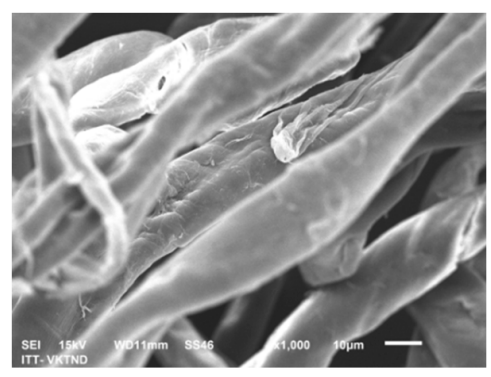

Pulp fiber

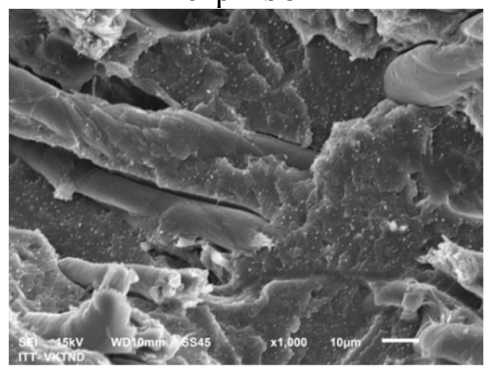

$20 \% \mathrm{NPF}$

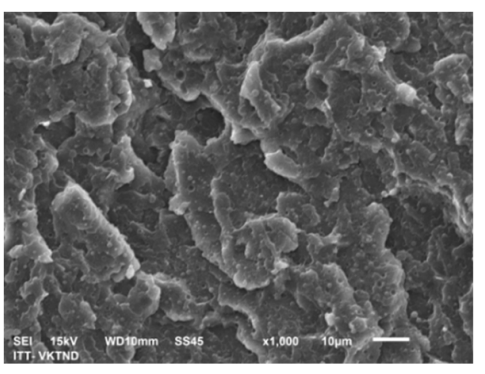

Neat PLA

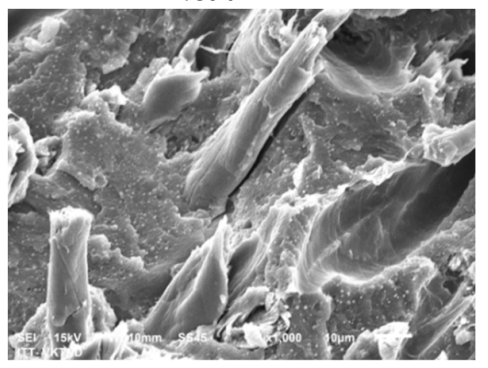

$30 \% \mathrm{NPF}$

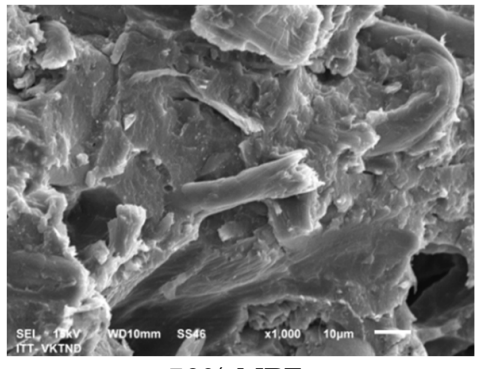

$50 \% \mathrm{NPF}$

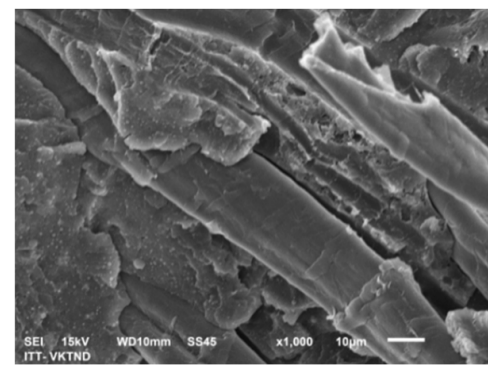

$10 \% \mathrm{NPF}$

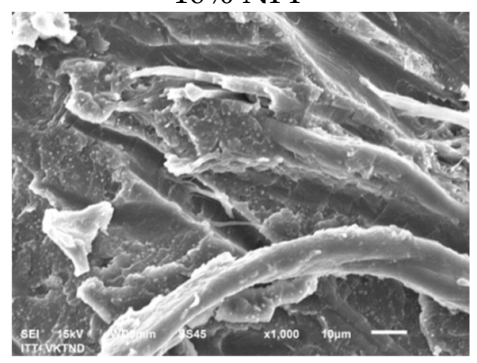

$40 \% \mathrm{NPF}$

Figure 4. SEM images of fractured surface of PLA/NPF composites with different NPF contents.
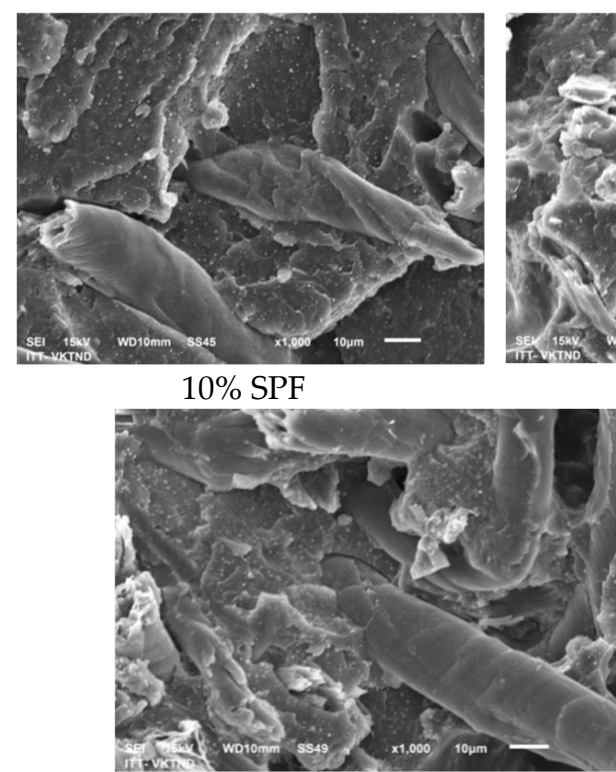

$40 \%$ SPF

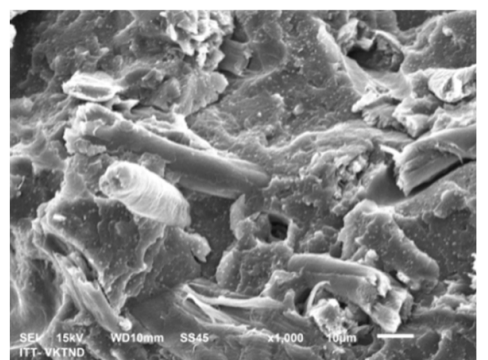

$20 \% \mathrm{SPF}$

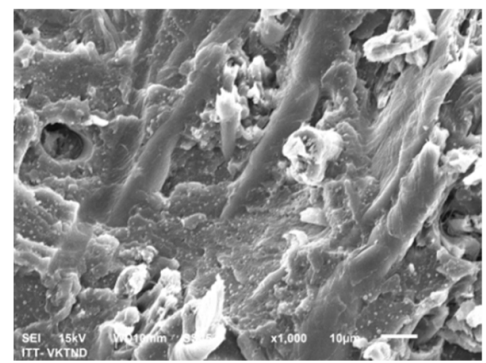

$30 \% \mathrm{SPF}$

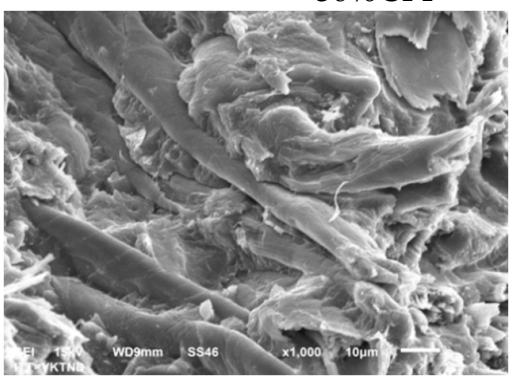

$50 \%$ SPF

Figure 5. SEM images of fractured surface of PLA/SPF composites with different SPF contents.

\subsubsection{Fourier Transfer Infrared Spectra}

The FTIR spectra of pulp fiber, ETO, PLA, PLA/SPF composites with 10, 30 and 50\% SPF were presented in Figure 6. 


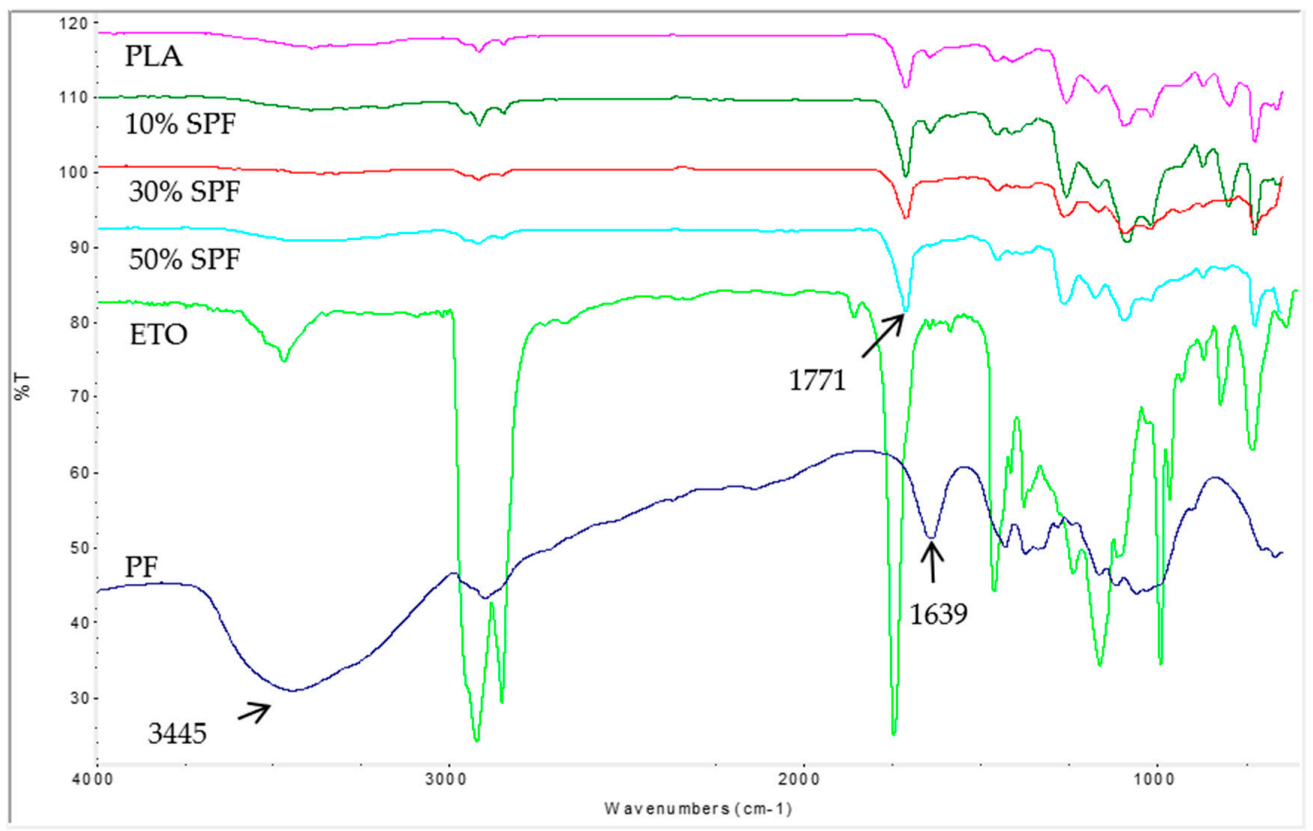

Figure 6. The FTIR spectra of pulp fiber, ETO, PLA, PLA/SPF composites with $10 \%$ SPF, 30 SPF and $50 \%$ SPF.

In IR spectrum of ETO, the peak at $1642 \mathrm{~cm}^{-1}$ which was assigned for $\mathrm{C}=\mathrm{C}$ disappeared. Instead there was appearance of a peak at $824 \mathrm{~cm}^{-1}$ which was assigned for C-O in epoxy ring [25]. This indicated that epoxidation of Tung oil had occurred. The IR spectrum of the pulp fiber appeared as a peak at $3445 \mathrm{~cm}^{-1}$, which was assigned for O-H stretching vibration. This peak of PLA/SPF composites increased by increasing SPF content. A peak at $1771 \mathrm{~cm}^{-1}$, which was assigned for $\mathrm{C}=\mathrm{O}$ group in PLA and ETO [16], also increased by increasing SPF content. This might be due to the increase of SPF content means that the ETO content in the composite also increased, so the concentration of $\mathrm{C}=\mathrm{O}$ group increased.

\subsubsection{Differential Scanning Calorimetry}

The thermal properties of the composites with different SPF fiber contents were investigated by Differential Scanning Calorimetry (DSC). The DSC results for PLA, PLA/SPF composite were listed in Table 4.

Table 4. Differential Scanning Calorimetry (DSC) results of PLA/SPF composites.

\begin{tabular}{cccc}
\hline Soaked Pulp Fiber Contents $(\%)$ & $\mathbf{T}_{\mathbf{g}}\left({ }^{\circ} \mathbf{C}\right)$ & $\mathbf{T}_{\mathbf{m}}\left({ }^{\circ} \mathbf{C}\right)$ & $\mathbf{T}_{\mathbf{c}}\left({ }^{\circ} \mathbf{C}\right)$ \\
\hline 0 & 56.2 & 148.1 & 86.4 \\
\hline 10 & 56.2 & 147.7 & 88.8 \\
\hline 20 & 54.8 & 146.5 & - \\
\hline 30 & 55.0 & 146.8 & - \\
\hline 40 & 53.5 & 146.9 & - \\
\hline 50 & 50.6 & 150.3 & - \\
\hline
\end{tabular}

The results showed that when the fiber content was 10-30\%, the glass transition $\left(\mathrm{T}_{\mathrm{g}}\right)$ temperature of PLA in the composite was almost insignificantly as compared to that of neat PLA. This indicated that there was no restriction on the mobility of the PLA chains when adding pulp fiber. Espinach et al. [26] also observed the same phenomenon when adding $20-25 \%$ of bleached kraft soft wood 
to PLA matrix. However, when the fiber content exceeded 30\%, the glass transition temperature of composites decreased.

The melting temperature ( $\mathrm{T}_{\mathrm{m}}$ ) of PLA in the composite, containing $10 \%$ fiber, was quite similar to that of neat PLA, but the crystallization temperature $\left(\mathrm{T}_{\mathrm{c}}\right)$ increased slightly. Meanwhile, at the fiber content of $20-50 \%$, the melting temperature of PLA decreased, compared to the composite, containing $10 \%$ of fiber and had no differences among samples. In addition, the crystallization temperature of these samples was not observed, and this change in crystallinity reduced the melting temperature of the composites.

\subsubsection{Thermogravimetry Analysis}

The thermal stability of PLA/SPF composites was investigated by thermogravimetry analysis method, and the results are shown in Figure 7. Data analysis from the thermal analysis curves of these composites was listed in Table 5.

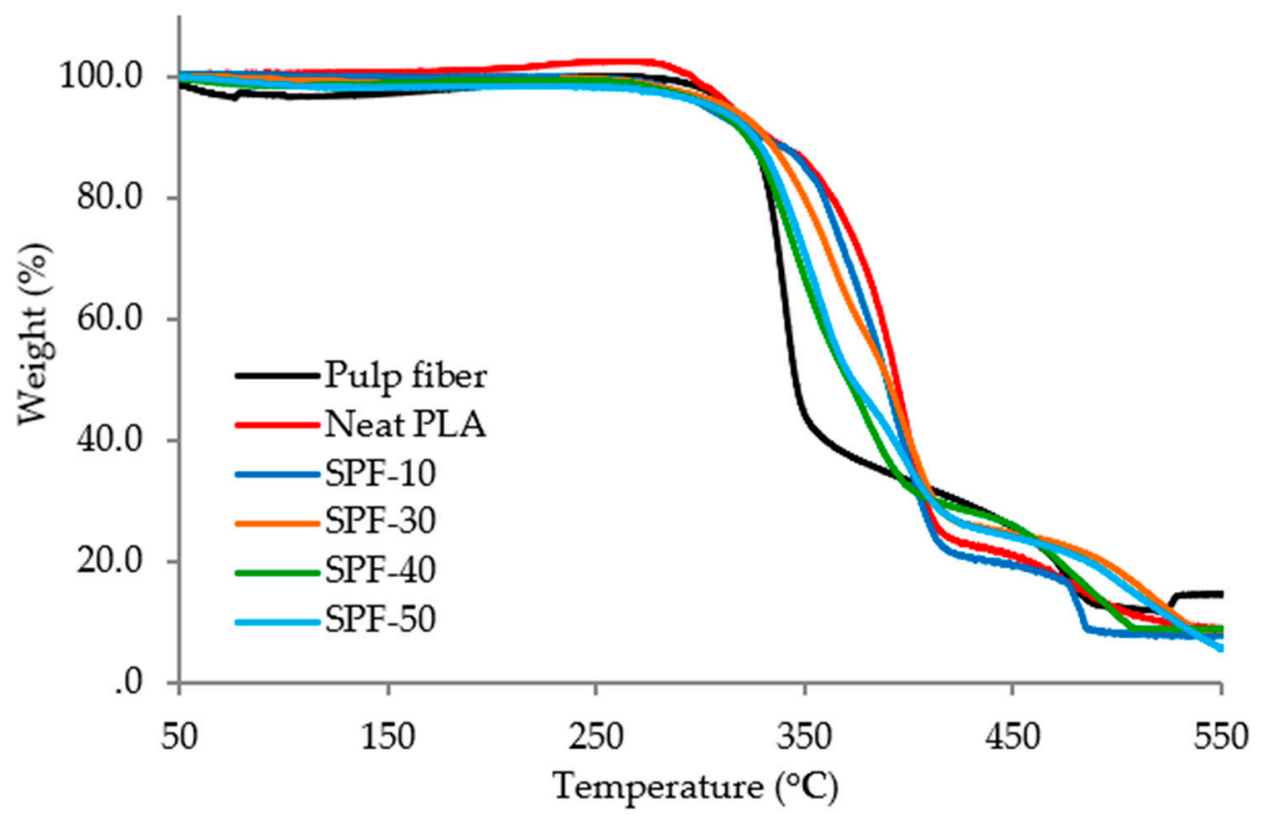

Figure 7. TGA curves of pulp fiber, PLA and PLA/SPF composites.

Table 5. Thermal analysis value of PLA and PLA/SPF composites.

\begin{tabular}{ccccc}
\hline Soaked Pulp Fiber Contents $(\mathbf{\%})$ & $\mathbf{T}_{\mathbf{5}}\left({ }^{\circ} \mathbf{C}\right)$ & $\mathbf{T}_{\mathbf{2 5}}\left({ }^{\circ} \mathbf{C}\right)$ & $\mathbf{T}_{\mathbf{5 0}}\left({ }^{\circ} \mathbf{C}\right)$ & Weight Loss at $\mathbf{4 5 0}{ }^{\circ} \mathbf{C}(\mathbf{\%})$ \\
\hline SPF & 314.6 & 335.9 & 346.3 & 74.37 \\
\hline 0 & 313.9 & 371.2 & 394.0 & 78.98 \\
\hline 10 & 302.8 & 365.0 & 389.3 & 80.61 \\
\hline 20 & 310.5 & 360.9 & 393.2 & 77.29 \\
\hline 30 & 312.7 & 356.9 & 390.0 & 75.39 \\
\hline 40 & 305.1 & 342.0 & 370.8 & 74.02 \\
\hline 50 & 306.1 & 346.0 & 372.9 & 79.68 \\
\hline
\end{tabular}

The pulp fiber decomposition process can be divided into 3 stages. The first stage was the process of losing moisture at about $100{ }^{\circ} \mathrm{C}$ with about a $3 \%$ of weight loss. The second stage takes place at about $280-410^{\circ} \mathrm{C}$ with a mass loss of $63.6 \%$. This weight-loss stage was due to the decomposition of the main components of the fibers which took place mainly in amorphous regions [27]. This stage can be the polymerization of hemicellulose [28] and the random cleavage of glycoside bonds in cellulose [29]. 
The results showed that TGA curves of PLA/SPF composites exhibited multiple steps. The decomposition stage takes place at about $300-410{ }^{\circ} \mathrm{C}$ due to the decomposition of the PLA polymer chains and the main components of pulp fibers. The stage at $410-480{ }^{\circ} \mathrm{C}$ is due to carbon burning. The results in Table 5 also indicated that the degradation temperature of composites was lower than that of neat PLA. The degradation temperature of PLA-based composites decreased by increasing the SPF fiber content. It might be due to the degradation temperature of SPF fiber was lower than that of neat PLA.

\subsection{Effect of Epoxidized Tung Oil Contents}

\subsubsection{Mechanical Properties of Composites}

In this study, the sample was prepared according to method 2 with different epoxidized Tung oil contents (0-15\%), but the ratio of PLA/pulp fiber was fixed at 70/30. Physical properties such as tensile strength, flexural strength of PLA/SPF composites were measured to evaluated effect of epoxidized Tung oil. Results of the mechanical tests were presented in Table 6.

Table 6. Mechanical properties of PLA/SPF composites with different percentages of epoxidized Tung oil.

\begin{tabular}{cccccc}
\hline $\begin{array}{c}\text { Epoxidized Tung Oil } \\
\text { Contents (\%) }\end{array}$ & $\begin{array}{c}\text { Tensile } \\
\text { Strength } \\
\mathbf{( M P a )}\end{array}$ & $\begin{array}{c}\text { Tensile Modulus } \\
\mathbf{( M P a )}\end{array}$ & $\begin{array}{c}\text { Elongation at } \\
\text { Break (\%) }\end{array}$ & $\begin{array}{c}\text { Flexural } \\
\text { Strength } \\
\mathbf{( M P a )}\end{array}$ & $\begin{array}{c}\text { Flexural } \\
\text { Modulus } \\
\mathbf{( G P a )}\end{array}$ \\
\hline 0 & $48.05 \pm 1.85$ & $2403.11 \pm 105.42$ & $2.19 \pm 0.08$ & $98.3 \pm 4.88$ & $2.93 \pm 0.12$ \\
\hline 5 & $50.52 \pm 2.09$ & $3219.22 \pm 96.23$ & $2.56 \pm 0.23$ & $102.1 \pm 5.03$ & $3.17 \pm 0.15$ \\
\hline 7.5 & $52.28 \pm 2.14$ & $3094.93 \pm 101.45$ & $3.71 \pm 0.40$ & $103.2 \pm 3.94$ & $3.34 \pm 0.09$ \\
\hline 10 & $59.32 \pm 2.35$ & $3043.54 \pm 96.52$ & $5.13 \pm 0.31$ & $114.7 \pm 3.67$ & $4.97 \pm 0.18$ \\
\hline 15 & $54.03 \pm 2.28$ & $2667.19 \pm 95.16$ & $5.45 \pm 0.30$ & $105.8 \pm 4.52$ & $4.19 \pm 0.16$ \\
\hline
\end{tabular}

The results showed that the mechanical properties of the composites with ETO, used as a plasticizer, were higher than those without ETO. The tensile strength increased from 50.52 to $59.32 \mathrm{MPa}$, elongation at break increased from 2.56 to $5.13 \%$, the flexural strength increased from 98.3 to $114.7 \mathrm{MPa}$ and flexural modulus increased from 3.17 to $4.97 \mathrm{GPa}$ when the ETO content increased from 5 to $10 \%$, but the tensile modulus decreased from 3219.22 to $3043.54 \mathrm{MPa}$. This indicated that the ETO improved the mechanical properties of the composites, due to the fact that the ETO also acted as a plasticizer for PLA, so it increased the flexibility of matrix and reduced its free surface energy. This had also been proved by several other authors [30]. However, when the content of the ETO in fiber exceeded 15\%, both strength and modulus reduced because it made the material softer. This phenomenon was also observed by Kirsi when using $12 \%$ of epoxidized linseed oil as a plasticizer for PLA/bleached softwood kraft pulp composites [26].

\subsubsection{Morphology Observation}

The fracture surface morphology of the ETO soaked pulp fiber reinforced PLA composites with different epoxidized Tung oil contents were presented in Figure 8. 


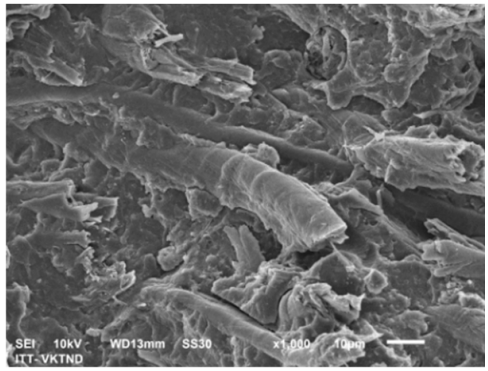

ETO-0

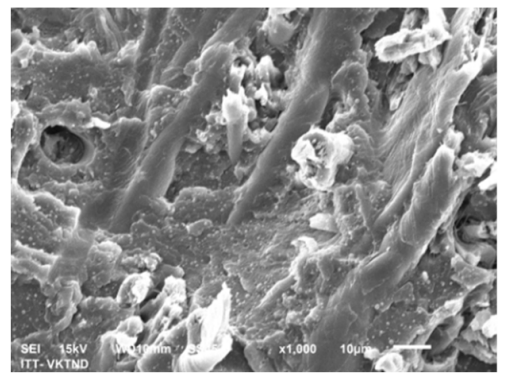

ETO-10

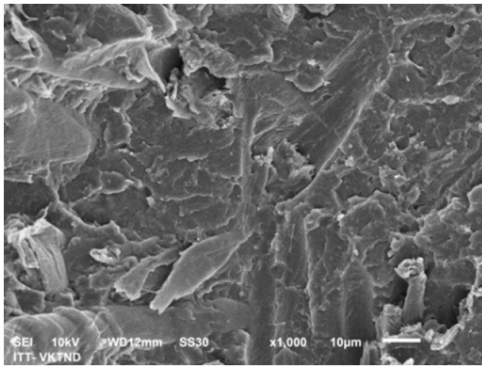

ETO-5

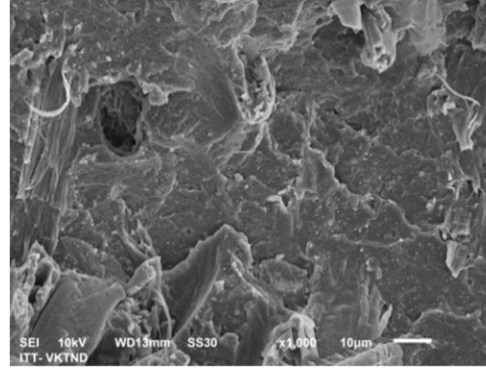

ETO-7.5

Figure 8. SEM picture of PLA/SPF composites with different contents of ETO.

The results showed that the composite without ETO can experience clear gaps between fiber and PLA. There was less phase separation between fiber and PLA when ETO was added to the number of fiber of $5-7.5 \%$. When the number of fiber in ETO content was 10\%, it was found that the pulp fibers showed more tight connections with PLA matrix. However, with ETO content with $15 \%$ of fiber, it seemed that the links between the pulp fiber and PLA were weakened, and there were gaps between the two surfaces.

\section{Conclusions}

This research suggested that pulp fiber could be successfully used as a reinforcement in PLA-based composites. The tensile properties of PLA/PF composites firstly increased after adding the fiber, and then decreased when the content of fiber was over 30\%. With the addition of PF fiber, the flexural modulus of PLA-based composites increased, but the flexural strength of them experienced no change. An improvement in the mechanical properties was possibly caused by PF reinforcement, as well as the efficient stress transfer between the PLA matrix and fiber. The PLA-based composite with $30 \%$ SPF fiber had the optimal mechanical properties; the tensile strength, tensile modulus, flexural strength and flexural modulus of this composite increased by $45.86 \%, 39.12 \%, 20.74 \%$, and $70.79 \%$, respectively, when compared with those of the neat PLA. In addition, the thermal stability of the PLA/PF composites decreased by the increase of the PF fiber.

The interaction between pulp fibers and PLA matrix improved, as the ETO content increased. The tensile and flexural strength of the composite increased by adding ETO with the percentage of 5-10\% content. The mechanical properties of composites reduced when the ETO content was high (in amount of $15 \%$ of fiber) because ETO acted as a plasticizer for PLA.

Author Contributions: Conceptualization: T.T.N. and T.H.P.T.; data curation: T.T.P.; formal analysis: T.T.N. and T.T.P.; investigation: T.T.N. and T.T.P.; methodology: T.T.N. and T.H.P.T.; project administration: V.K.N.; software: T.H.P.T. and T.T.P.; writing—original draft: T.H.P.T. and T.T.P.; writing-review and editing: V.K.N. and T.T.P. All authors have read and agreed to the published version of the manuscript.

Funding: This research received no external funding.

Conflicts of Interest: The authors declare no conflict of interest. 


\section{References}

1. Naudu, A.L.; Ramana Rao, P.S.V. A review on chemical behaviour of natural fiber composites. Int. J. Chem. Sci. 2016, 14, 2223-2238.

2. Karim, M.A.A.; Zaman, I.; Rozlan, S.A.M.; Berhanuddin, N.I.C.; Manshoor, B.; Mustapha, M.S.; Khalid, A.; Chan, S.W. Structural characterization and mechanical properties of polypropylene reinforced natural fibers. J. Phys. Conf. Ser. 2017, 94, 012035. [CrossRef]

3. Michael, A.F.; Huo, S.; Ulven, C.A. Natural fiber reinforced composites. Polym. Rev. 2012, 52, $259-320$.

4. Rohit, K.; Dixit, S. Areview-Future aspect of natural fiber reinforced composite. Polym. Renew. Resour. 2016, 7, 43-60.

5. Bax, B.; Müssig, J. Impact and tensile properties of PLA/Cordenka and PLA/flax composites. Comp. Sci. Technol. 2008, 68, 1601-1607. [CrossRef]

6. Duigou, A.L.; Davies, P.; Baley, C. Macroscopic analysis of interfacial properties of flax/PLLA biocomposites. Compos. Sci. Technol. 2010, 70, 1612-1620. [CrossRef]

7. Kumar, R.; Yakubu, M.K.; Anandjiwala, R.D. Biodegradation of flax fiber reinforced poly lactic acid. Express. Polym. Lett. 2010, 4, 423-430. [CrossRef]

8. Plackett, D. Biodegradable composites based on L-polylactide and jute fibers. Comp. Sci. Technol. 2003, 63, 1287. [CrossRef]

9. Hu, R.H.; Jang, M.H.; Kim, Y.J.; Piao, Y.J.; Lim, J.K. Fully Degradable Jute Fiber Reinforced Polylactide Composites Applicable to Car Interior Panel. Adv. Mater. Res. 2010, 123, 1151-1154. [CrossRef]

10. Graupner, N.; Herrmann, A.S.; Müssig, J. Natural and man-made cellulose fibre-reinforced poly(lactic acid) (PLA) composites: An overview about mechanical characteristics and application areas. Compos. Pt A Appl. Sci. Manuf. 2009, 40, 810-821. [CrossRef]

11. Tholibona, D.; Tharazia, I.; Sulonga, A.B.; Muhamada, N.; Ismaila, N.F.; Radzia, M.K.F.M.; Radzuand, N.A.M.; Hui, D. Kenaf Fiber Composites: A Review on Synthetic and Biodegradable Polymer Matrix. J. Kejuruteraan. 2019, 31, 65-76.

12. Tharazi, I.; Muhamad, N.; Ismail, N.F.; Radzi, M.K.F.M.; Razak, Z. Effects of Fiber Content and Processing Parameters on Tensile Properties of Unidirectional Long Kenaf Fiber Reinforced PolylacticAcid Composite. J. Mech. Eng. 2017, 3, 65-76.

13. Bledzki, A.K.; Jaszkiewicz, A.; Scherzer, D. Mechanical properties of PLA composites with man-made cellulose and abaca fibres. Compos. Pt A Appl. Sci. Manuf. 2009, 40, 404-412. [CrossRef]

14. Masirek, R.; Kulinski, Z.; Chionna, D.; Piorkowska, E.; Pracella, M. Composites of Poly(L-lactide) with Hemp Fibers: Morphology and Thermal and Mechanical Properties. J. Appl. Polym. Sci. 2007, 105, 255-268. [CrossRef]

15. Yang, Z.; Feng, X.; Bi, Y.; Zhou, Z.; Yue, J.; Xu, M. Bleached extruder chemi-mechanical pulp fiber-PLA composites: Comparison of mechanical, thermal, and rheological properties with those of wood flour-PLA bio-composites. J. Appl. Polym. Sci. 2016, 133, 44241. [CrossRef]

16. Immonen, K.; Anttila, U.; Wikström, L. Coupling of PLA and bleached softwood kraft pulp (BSKP) for enhanced properties of biocomposites. J. Compos. Mater. 2019, 32, 328-341. [CrossRef]

17. Peltola, H.; Immonen, K.; Johansson, L.-S.; Virkajärvi, J.; Sandquist, D. Influence of pulp bleaching and compatibilizer selection on performance of pulp fiber reinforced PLA biocomposites. J. Appl. Polym. Sci. 2019, 136, 47955. [CrossRef]

18. Gardner, H.A.; Sward, G.G. Part 2: Raw materials, Chapter 2.1. Drying oils. In Paint Testing Manual: Physical and Chemical Examination of Paints, Varnishes, Lacquers, and Colors, 3rd ed.; Sward, G.G., Ed.; American Society for Testing and Materials: West Conshohocken, PA, USA, 1972; pp. 53-70.

19. Aniket, E.K.; Disha, G.; Preeti, S.Z.; Manoj, B.M. Recent Advances in Epoxidation of Vegetable oils. Int. J. Emerg. Technol. Innova. Res. 2017, 4, 171-175.

20. Hajba, S.; Tábi, T. Development of natural fibre reinforced poly (lactic acid) biocomposites. In Proceedings of the ECCM16-16th European Conference on Composite Materials, Seville, Spain, 22-26 June 2014.

21. Qian, J.; Yu, M.; Ge, Z.; Xu, M.; Zhang, H.; Yang, G.; Shao, H. Preparation and properties of cotton fiber/poly (lactic acid) composites. Mater. Sci. Forum. 2014, 789, 100-105. [CrossRef] 
22. Chieng, B.W.; Ibrahim, N.A.; Then, Y.Y.; Loo, Y.Y. Epoxidized Vegetable Oils Plasticized Poly(lactic acid) Biocomposites: Mechanical, Thermal and Morphology Properties. Molecules 2014, 19, 16024-16038. [CrossRef] [PubMed]

23. Nabinejad, O.; Sujan, D.; Rahman, M.E.; Davies, I.J. Effect of filler load on the curing behavior and mechanical and thermal performance of wood flour filled thermoset composites. J. Clean. Prod. 2017, 164, 1145-1156. [CrossRef]

24. Baba, B.O.; Özmen, U. Preparation and mechanical characterization of chicken feather/PLA composites. Polym. Compos. 2017, 38, 837-845. [CrossRef]

25. Chang, B.P.; Thakur, S.; Mohanty, A.K.; Misra, M. Novel sustainable biobased flame retardant from functionalized vegetable oil for enhanced fame retardancy of engineering plastic. Sci. Rep. 2019, 9, 15971. [CrossRef] [PubMed]

26. Espinach, F.X.; Boufi, S.; Delgado-Aguilar, M.; Julián, F.; Mutjé, P.; Méndez, J.A. Composites from poly(lactic acid) and bleached chemical fibres: Thermal properties. Compos. Part B Engine 2018, 134, 169-176. [CrossRef]

27. Jonoobi, M.; Niska, K.O.; Harun, J.; Misra, M. Chemical composition, crystallinity, and thermal degradation of bleached and unbleached kenaf bast (Hibiscus cannabinus) pulp and nanofibers. Bioresource 2009, 4, 626-639.

28. Kim, H.S.; Kim, S.; Kim, H.J.; Yang, H.S. Thermal properties of bio-flour-filled polyolefin composites with different compatibilizing agent type and content. Thermochim. Acta 2006, 451, 181-188. [CrossRef]

29. Poletto, M.; Zattera, A.J.; Forte, M.M.; Santana, R.M. Thermal decomposition of wood: Influence of wood components and cellulose crystallite size. Bioresour. Technol. 2012, 109, 148-153. [CrossRef]

30. Menčík, P.; Přikryl, R.; Stehnová, I.; Melčová, V.; Kontárová, S.; Figalla, S.; Alexy, P.; Bočkaj, J. Effect of selected commercial plasticizers on mechanical, thermal, and morphological properties of poly(3-hydroxybutyrate)/poly(lactic acid)/plasticizer biodegradable blends for three-dimensional (3d) print. Materials 2018, 11, 1893. [CrossRef]

(C) 2020 by the authors. Licensee MDPI, Basel, Switzerland. This article is an open access article distributed under the terms and conditions of the Creative Commons Attribution (CC BY) license (http://creativecommons.org/licenses/by/4.0/). 